\title{
An Update on Dentinal Hypersensitivity - Aetiology to Management - A Review
}

\author{
Mrinalini $^{1}$, Urvashi B. Sodvadiya ${ }^{2}$, Mithra N. Hegde ${ }^{3}$, Gowrish S. Bhat ${ }^{4}$ \\ 1, 2, 3, 4 Department of Conservative Dentistry and Endodontics, AB Shetty \\ Memorial Institute of Dental Sciences, Mangalore, Karnataka, India.
}

\section{ABSTRACT}

\section{BACKGROUND}

Dentinal hypersensitivity is a common clinical disease that occurs as a result of dentin exposure. Though the term dentin hypersensitivity and dentin sensitivity is used interchangeably, dentin hypersensitivity is an exaggerated form of dentinal sensitivity which arises due to localized pulpal inflammation, pulpal nerve sprouting, and development of inflammatory sodium channels. It is characterised by short sharp pain emerging from exposed dentinal tubules in reaction to various stimuli. Such dentin exposure could be due to either enamel loss or cemental loss. This is followed by removal of smear layer by mechanical or chemical means. At present, the hydrodynamic theory, which describes fluid movement in response to stimuli within exposed dentinal tubules, is a commonly recognized explanation for dentin hypersensitivity. It is more common in premolars and canines, and it affects the facial surfaces of the teeth towards the cervical aspect. Studies suggested microscopic changes in the structure of sensitive dentin compared with normal dentin. The diagnosis of dentinal hypersensitivity requires careful clinical examination and eliciting the response using various stimuli. Dentinal hypersensitivity is usually managed by the use of physical or chemical agents. They work either by disturbing the neural response to pain stimulus or block fluid flow by occluding the tubule. The desirable features of a desensitising agent include the ability to give instant and longlasting pain relief, being simple to use, well accepted, not harmful to the pulp. It is recommended that the desensitizing agent is used for at least two weeks. Some of the newer agents used for management includes CPP-ACP, proarginine, nanomaterials, herbal products, propolis etc. In cases where there is tooth structure loss, appropriate restorative material is used to cover the exposed dentin. Root canal therapy is considered the last resort for pain relief after all other options have failed to provide relief. The present article outlines the etiopathogenesis, risk factors, diagnosis, prevention and treatment of dentinal hypersensitivity.

\section{KEY WORDS}

Dentinal Hypersensitivity; Dentin Sensitivity; Desensitizing Agents; Iontophoresis
Corresponding Author: Dr. Urvashi B. Sodvadiya, Third Floor, AB Shetty Memorial Institute of Dental Sciences, Mangalore, Karnataka, India. E-mail: urvashisodvadiya@gmail.com

DOI: $10.14260 /$ jemds/2021/667

How to Cite This Article: Mrinalini, Sodvadiya UB, Hegde MN, et al. An update on dentinal hypersensitivity aetiology to management - a review. J Evolution Med Dent Sci 2021;10(37):32893293, DOI: 10.14260/jemds/2021/667

Submission 21-05-2021,

Peer Review 09-08-2021,

Acceptance 16-08-2021,

Published 13-09-2021.

Copyright (C) 2021 Mrinalini et al. This is an open access article distributed under Creative Commons Attribution License [Attribution 4.0 International (CC BY 4.0)] 


\section{BACKGROUND}

Dentinal hypersensitivity is defined as short, sharp pain arising from exposed dentin in response to stimuli, typically thermal, evaporative, tactile, osmotic, and chemical which cannot be ascribed to any other dental defect or pathology. ${ }^{1}$ It is also known as common cold of dentistry, tooth brush disease, dentin hyperesthesia, sensitivity, and root or cervical or dentin or cemental sensitivity depending on the location. 2,3 The prevalence of dentin hypersensitivity is $15-80 \%$ in general population whereas it increases in periodontal patients. ${ }^{4}$ Usually age group of 20 - 50 years is most affected as appearance or progression of gingival recession is most common during this age group. As the age advances due to sclerotic or tertiary dentin formation, pulpal changes, decrease in permeability and fibrosis of pulp overall reduces the hydraulic conductance of dentin thereby sensitivity of tooth. Often female are more affected than male and it is more common in maxilla than mandible. ${ }^{3}$ Due to presence of thinnest enamel and site of gingival recession, cervical area is mostly affected. ${ }^{5}$

\section{Aetiology of Dentin Hypersensitivity}

The aetiology can be broadly divided into 2 processes: Lesion localization and lesion initiation.

\section{Lesion Localization}

Starts due to dentin exposure due to either enamel loss or cemental loss. The various factors attributed are gingival recession, attrition, abrasion, erosion, abfraction, improper instrumentation, and lack of overlap between enamel and cementum at cemento-enamel junction (CEJ). 6,7

\section{Lesion Initiation}

This process requires the opening of dentinal tubules. Toothpaste with abrasives, erosive agents, etc lead to removal of smear layer after few minutes of exposure and causes bulk loss of dentin. The smear layer is composed of elements of protein and sediments derived from salivary calcium phosphate and seal the tubule inconsistently and transiently. Both mechanical and chemical exposure is required for loss of the smear layer. ${ }^{8}$

\section{Normal vs Sensitive Vs Hypersensitive Dentin}

It was observed that sensitive dentin has 8 times more tubules which are thicker than that of normal dentin. Dentinoenamel junction is said to be the most sensitive because of profuse branching of tubules. ${ }^{9}$ Dentinal tubules first exposed become sensitive to tactile, evaporative, and osmotic stimuli. Over time because of poor plaque control, continuous seepage of bacterial products, it becomes hypersensitive. This conversion is attributed to localized pulpal inflammation, sprouting of pulpal nerves, and expression of inflammatory sodium channels. ${ }^{10}$ Theories related to the mechanism of dentinal hypersensitivity.

1. Direct innervations theory: This theory states that nerve endings penetrate the dentinoenamel junction and an action potential is triggered when these nerves are stimulated mechanically. ${ }^{11}$ As per the theory, the entire length of the tubule contains free nerve endings. However, microscopic studies suggested that neural cells in outer dentin are unlikely. Also, the plexus of Raschkow do not establish till the teeth erupt yet newly erupted teeth are sensitive. ${ }^{9}$

2. Odontoblastic transduction theory: Proposed by Rapp et al. ${ }^{12}$ This theory states that odontoblasts extend to the periphery. Stimuli initially excites the odontoblastic process. Since the membrane of the odontoblast is in close apposition with that of nerve ending in pulp, they transmit excitation to the associated nerve endings. However, studies suggested that odontoblasts are restricted only to the inner third of the tubule and no synapse was seen between odontoblast and nerve terminals. ${ }^{5}$

3. Hydrodynamic theory: This is the most acceptable theory at present and was given by Brannstorm in 1964. The stimulus causes displacement of fluid that activates the nerve endings particularly A-delta fibers. This displacement can be outward or inward. ${ }^{13}$ Stimuli like cold cause outward movement of fluid and produces more rapid and greater pulp response than heat.

Dehydration of dentin by air blast or absorbent paper also leads to outward movement of fluid resulting in pain.

Lin, Min et al. in 2011 showed that cold stimulus causes constriction of tubule that results in close approximation between odontoblastic process and nerve fiber resulting in increased stress and increased pain. ${ }^{14}$

Risk Factors for Dentinal Hypersensitivity: ${ }^{15}$

- Overenthusiastic brushers

- Habit of chewing smokeless tobacco

- Gingival recession

- Bulimics

- High acid food intake

- Xerostomia

- Poor oral hygiene

\section{Diagnosis of Dentinal Hypersensitivity}

- Case history: Includes nature of pain, intensity, frequency, duration, and stimuli causing pain.

- Examination: Various tests like radiographic examination, percussion test, and vitality test to rule out pulpal involvement are done.5,16

- Tactile or mechanical stimulus: This is done using No. 23 explorer with a force of $5-10 \mathrm{gm}$.

- Thermal stimulus: Using cold-water of varying temperature and heat test (Gutta percha, hot water) or blowing air from a distance of $1 \mathrm{~cm}$.

- Osmotic test: Cotton applicator saturated with sucrose solution is applied for a period of 10 seconds. ${ }^{17}$

- Scratch device: Made by Smith and Asc in 1964. In this, stainless steel wire moves along the highest arc of curvature on the facial surface of the sensitive tooth. Scratching force could be increased by a screw. A tooth that fails to respond at 80 centinewtons is said to be nonsensitive.

- Yeaple probe: It is a pen-like device that was introduced in 1990. It contains a handpiece with a probe tip and electronic control unit that allows the force of $0.05-1$ N.18 


\section{Differential Diagnosis}

Differential diagnosis includes dental caries, cracked tooth syndrome, fractured restoration, chipped teeth, enamel invaginations, bleaching sensitivity, teeth in acute hyper function, and post-operative sensitivity. ${ }^{19}$

\section{Management of Dentinal Hypersensitivity}

Prevention of Dentinal Hypersensitivity 5

- Avoid abrasive toothpaste

- Use of soft brush

- Correction of premature occlusal contact using splint and occlusal adjustments

- Diet counselling

- Oral hygiene instructions

- Management of gingival recession

\section{Treatment of Dentinal Hypersensitivity}

Classification (Scherman and Jacobeen, 1992)20

- Chemical agents: Corticosteroids, Silver nitrate, Strontium chloride, Formaldehyde, Fluoride, Sodium nitrate, Potassium nitrate or oxalate.

- Physical agents: Composites, Resins, Varnishes, Sealants, Glass Ionomer Cement, Lasers

Based on mode of administration

- In - office

- At home

Based on mechanism of action

- Disturbs neural response to pain stimulus

- Block fluid flow and occlude tubule ${ }^{5}$

\section{MECHANISM OF ACTION OF DESENSITISING AGENTS}

The primary aim of the desensitising agent is to limit the displacement of dentinal fluid which is attained by various mechanisms. These include formation of smear layer produced by burnishing the exposed surface, formation of insoluble precipitate within the dentinal tubule, impregnation or sealing of tubules with plastic resins and precipitation of crystalline salts on dentin surface. At least 2-week application of desensitising agent is recommended. The ideal properties of desensitising agent include its ability to provide immediate and lasting relief from pain, easy to apply, well tolerated, not injurious to pulp, does not stain teeth and inexpensive. ${ }^{21}$

\section{Strontium Chloride}

This is one of the earliest desensitising agents to be used. Invitro studies suggested slight reduction in dentinal fluid flow after application of $10 \%$ strontium chloride as the abrasive filler occludes the tubule orifice. ${ }^{22}$ They were made available in toothpaste form and combined with fluoride and formaldehyde. However, formaldehyde leads to destruction of vital components of the teeth.

\section{Potassium Chloride}

This agent works by decreasing the excitability of intra dental nerves. ${ }^{23}$ However, the effect was temporary. Pashley concluded that potassium chloride is ineffective even at a concentration as high as $30 \%$ in in-vitro study. ${ }^{24}$

\section{Varnish}

$5 \%$ sodium fluoride was recommended by Clark et al. in 1985 for temporary relief from pain due to hypersensitivity. Copal varnish was also used as a desensitising agent. ${ }^{25,26}$

\section{Corticosteroids}

Apart from completely obliterating the dentin, corticosteroids also possess anti-inflammatory effect. They are said to induce remineralisation leading to occlusion of the dentinal tubule. ${ }^{27}$

\section{Silver Nitrate}

It is a powerful protein precipitate which may cause pulpal damage. Most of the studies concluded it to be ineffective and suggested its deleterious effect. Silver nitrate is not commonly utilized, according to Markowitz and Kim, because it permanently colours the teeth. ${ }^{28}$

\section{Calcium Hydroxide}

Calcium hydroxide blocks the dentinal tubule by promoting peritubular dentin formation and reducing nerve excitability. ${ }^{29}$

\section{Hydroxyapatite}

Shetty et al. suggested hydroxyapatite to be an effective desensitising agent and provides quick relief. ${ }^{30}$

\section{Fluoride}

It leads to reparative dentin formation due to the formation of insoluble calcium fluoride precipitate. Though it was effective in reducing the sensitivity but caused pulpal inflammation in few cases. Formulations of fluoride include stannous fluoride, sodium monofluorophosphate and fluorosilicate. ${ }^{5}$

\section{Oxalates}

Forms precipitate named as calcium oxalate. It is inexpensive, easy to apply, well-tolerated, and short-lived. Long-term use of potassium oxalate results in digestive problems.

\section{Iontophoresis}

Use of an electric potential to transfer ions into the body for therapeutic purposes. A chemical substance is applied on the tooth surface and current is passed through negative electrode using $0.5 \mathrm{~mA}$ current. The chemicals used are fluoride, oxalates, etc. This process is said to increase the impregnation of the chemical by 2 to 6 times. ${ }^{31}$ 


\section{Burnishing of Dentin}

Burnishing is done by a toothpick, orangewood stick, or hand instruments. It leads to the formation of a partial smear layer which reduces the fluid movement by $50-80 \%$. Pashley compared various agents like sodium fluoride, Kaolin, glycerine alone and in various combinations and concluded that burnishing is the important variable rather than the chemical agents used. ${ }^{32}$

\section{Lasers}

Most commonly used lasers include Nd: YAG and Er: YAG. It acts by occluding the tubule via coagulation of protein of the fluid and also affects the neural transmission of the tubule. ${ }^{33}$

\section{Restorative Methods}

Commonly used materials are composites and glass ionomer cement. The effect is long-lasting and is indicated only if there is a loss of tooth structure. ${ }^{19}$

\section{NEWER AGENTS FOR THE MANAGEMENT OF HYPERSENSITIVITY}

- Casein-phosphopeptide-amorphous calcium phosphate (CPP) - (ACP) - A minimum of 6 weeks of topical application is recommended. It prevents the dissociation of calcium and phosphate ions and maintains their availability. ${ }^{34}$

- Pro-Arginine Technology - Arginine being positive charge binds to negatively charged tubule. It plugs and seals the tubule and makes them resistant to acid. Usually, the effect lasts for a minimum of 28 days. ${ }^{6}$

- Nanomaterials - It includes material with a dimension less than $100 \mathrm{~nm}$. This works by occluding the tubule and lasts a minimum of 7 days. The agents from this group include nanostructure bioactive glass, no Vamin, nanohydroxyapatite. 35

- Others - Portland cement, Propolis, etc.

However, many times these agents fail to provide relief. In such scenarios, root canal treatment is considered as the last resort for relief of pain. ${ }^{5}$

\section{CONCLUSIONS}

Dentinal hypersensitivity is a common problem affecting over $80 \%$ of the general population. It is characterized by sharp transient pain in response to stimulus and is associated with dentin exposure and the diagnosis is made after excluding another dental defect. The most accepted theory for dentinal hypersensitivity is fluid hydrodynamic theory. Management of dentinal hypersensitivity is mainly aimed at either blocking the fluid flow by occlusion of dentinal tubule or disturb the neural response to pain stimulus.

Financial or other competing interests: None.

Disclosure forms provided by the authors are available with the full text of this article at jemds.com.

\section{REFERENCES}

[1] Holland GR, Narhi MN, Addy M, et al. Guidelines for the design and conduct of clinical trials on dentine hypersensitivity. J Clin Periodontol 1997;24(11):803-13.

[2] Strassler HE, Drisko CL, Alexander DC. Dentin hypersensitivity: its inter-relationship to gingival recession and acid erosion. Compend Contin Educ Dent 2008;29(5):1-9.

[3] Davari AR, Ataei E, Assarzadeh H. Dentin hypersensitivity: etiology, diagnosis and treatment; a literature review. J Dent (Shiraz) 2013;14(3):136-45.

[4] Que K, Guo B, Jia Z, et al. A cross-sectional study: noncarious cervical lesions, cervical dentine hypersensitivity and related risk factors. J Oral Rehabil 2013;40(1):24-32.

[5] Miglani S, Aggarwal V, Ahuja B. Dentin hypersensitivity: recent trends in management. J Conserv Dent 2010;13(4):218-24.

[6] Cummins D. Recent advances in dentin hypersensitivity: clinically proven treatments for instant and lasting sensitivity relief. Am J Dent 2010;23(Spec No A):3A-13A.

[7] Addy M. Dentine hypersensitivity: definition, prevalence, distribution and aetiology. Tooth Wear and Sensitivity: Clinical Advances in Restorative Dentistry 2000;2000:239-48.

[8] Borges A, Barcellos D, Gomes C. Dentin hypersensitivityetiology, treatment possibilities and other related factors: a literature review. World Journal of Dentistry 2012;3(1):60-7.

[9] Orchardson R, Gillam DG. Managing dentin hypersensitivity. J Am Dent Assoc 2006;137(7):990-8.

[10] Pashley DH. How can sensitive dentine become hypersensitive and can it be reversed? J Dent 2013;41(Suppl 4):S49-55.

[11] Irvine JH. Root surface sensitivity: a review of aetiology and management. J N Z Soc Periodontol 1988;66:15-8.

[12] Rapp R, Avery JK, Strachan DS. Possible role of acetylcholinesterase in neural conduction within the dental pulp. In: Finn B, ed. Biology of the dental pulb organ. A symposium. Birmingham: University of Alabama Press 1968:309-25.

[13] Braennstrom M, Astroem A. A study on the mechanism of pain elicited from the dentin. J Dent Res 1964;43:619-25.

[14] Lin M, Luo ZY, Bai BF, et al. Fluid mechanics in dentinal microtubules provides mechanistic insights into the difference between hot and cold dental pain. PLoS One 2011;6(3):e18068.

[15] Gillam DG, Orchardson R. Advances in the treatment of root dentine sensitivity-mechanisms and treatment principles. Endodontic Topics 2006;13(1):13-33.

[16] Dowell P, Addy M. Dentine hypersensitivity: a review: aetiology, symptoms and theories of pain production. J Clin Periodontol 1983;10(4):341-50.

[17] Gillam DG. Current diagnosis of dentin hypersensitivity in the dental office: an overview. Clin Oral Investig 2013;17(Suppl 1):21-9.

[18] Garcia-Godoy F, Trushkowsky RD. A diagnostic device to record dentin hypersensitivity. Am J Dent 2013;26(Spec No B):3B-4B.

[19] Liu XX, Tenenbaum HC, Wilder RS, et al. Pathogenesis, diagnosis and management of dentin hypersensitivity: an 
evidence-based overview for dental practitioners. BMC Oral Health 2020;20(1):1.

[20] Scherman A, Jacobsen PL. Managing dentin hypersensitivity: what treatment to recommend to patients. J Am Dent Assoc 1992;123(4):57-61.

[21] Grossman L. A systematic method for the treatment of hypersensitive dentine. J Am Dent Assoc 1935;22(4):5928.

[22] Uchida A, Wakano Y, Fukuyama O, et al. Controlled clinical evaluation of a $10 \%$ strontium chloride dentifrice in treatment of dentin hypersensitivity following periodontal surgery. J Periodontol 1980;51(10):578-81.

[23] Markowitz K, Bilotto G, Kim S. Decreasing intradental nerve activity in the cat with potassium and divalent cations. Arch Oral Biol 1991;36(1):1-7.

[24] Greenhill JD, Pashley DH. The effects of desensitizing agents on rhe hydraulic conductance of human dentin in vitro. J Dent Reb 1981;60(3):686-98.

[25] Clark DC, Hanley S, Geoghean S, et al. The effectiveness of fluoride varnish and desensitizing toothpaste in treating dentinal hypersensitivity. J Periodontal Res 1985;20(2):212-9.

[26] Hack GD, Thompson VP. Occlusion of dentinal tubules with cavity varnishes. Archs Oral Biol 1994;39:S149.

[27] Nirola A, Gupta M, Singla K, Kaur M. Comparative efficacy of application of three different desensitizing agents with iontophoresis in the treatment of hypersensitive teeth. Journal of the International Clinical Dental Research Organization 2016;8(1):51.
[28] Markowitz K, Kim S. Hypersensitive teeth. Experimental studies of dentinal desensitizing agents. Dent Clin North Am 1990;34(3):491-501.

[29] Mjor IA, Furseth R. The inorganic phase of calcium hydroxide and corticosteroid covered dentine studied by electron microscopy. Arch Oral Biol 1968;13(7):755-63.

[30] Shetty S, Kohad R, Yeltiwar R. Hydroxyapatite as an inoffice agent for tooth hypersensitivity: a clinical and scanning electron microscopic study. J Periodontol 2010;81(12):1781-9.

[31] Yadav BK, Jain A, Rai A, et al. Dentine hypersensitivity: a review of its management strategies. Journal of International Oral Health 2015;7(10):137-43.

[32] Pashley DH, Leibach JG, Horner JA. The effects of burnishing $\mathrm{NaF} / \mathrm{kaolin} /$ glycerin paste on dentin permeability. J Periodontol 1987;58(1):19-23.

[33] Pashley DH. Potential treatment modalitiesfor dentine hypersensitivity: in office products. In: Addy M, Embery G, Edgar WM, et al, eds. Tooth Wear and Sensitivity: Clinical Advances in Restorative Dentistry. London: Martin Dunitz 2000:351-65.

[34] Cai F, Shen P, Morgan MV, et al. Remineralization of enamel subsurface lesions in situ by sugar-free lozenges containing casein phosphopeptide-amorp-hous calcium phosphate. Aust Dent J 2003;48(4):240-3.

[35] Wang L, Magalhães AC, Francisconi-Dos-Rios LF, et al. Treatment of dentin hypersensitivity using nanohydroxyapatite pastes: a randomized three-month clinical trial. Oper Dent 2016;41(4):E93-101. 